\title{
LEPTOSPIROSE EM ANIMAIS DO BIOTÉRIO CENTRAL DO CENTRO DE CIÊNCIAS BIOLÓGICAS DA UNIVERSIDADE ESTADUAL DE LONDRINA
}

\author{
DONIZETI RODRIGUES BELITARDO \\ JÚLIO CÉSAR DE FREITAS 2 \\ ERNST ECKEHARDT MÜLLER 2
}

\begin{abstract}
BELITARDO; D. R.; FREITAS, J. O. ; MÜLLER, E. E. Leptospirose em animais do Biotério Central do Centro de Ciências Biológicas da Universidade Estadual de Londrina. Semina: Ci- Agrárias, Londrina; v. 21 .n. 1, p. 19-25, mar. 2000.
\end{abstract}

\begin{abstract}
RESUMO: A leptospirose tem sido descrita em biotérios de vários países, acometendo camundongos. ratos albinos, cobaios, cães, coelhos e macacos além do manipuladores. $O$ Biotério Centrai do Centro de Ciências Biológicas da Universidade Estadual de Londrina mantém e cria várias espécies de animais além de receber cães de rua, capturados em municípios do Estado do Paraná. Neste trabalho foram utilizados para a pesquisa de leptospirose, soros de 325 ratos wistar, 323 camundongos albinos. 289 cães de rua, 135 coelhos, 119 cobaios, além de 57 ratos pretos capturados nas proximidades do biotério. A prova de somaglutinação microscópica com 22 soroiipos de Lepiospira interrogans mostrou resultados positivos em 110 cães e um cobaio, sendo encontrado anticorpos principalmente contra os soroiipos canicola (62. 7\%). pyrogenes (51.8\%). castellonis (30,9\%) e icterohaemorrhagiae (23.6\%). A pesquisa direta de leptospira em 574 amostras de urina (282 camundongos, 224 ratos wistar, 29 ratos pretos, 24 cães. 13 coelhos e dois cobaios) em microscópio dc campo escuro apresentou resultado positivo em seis cães. Não foi possível o isolamento de Leptospira spp em sete amostras de rins e urina.
\end{abstract}

PALAVRAS-CHAVE: Leptospirose, biotério, soroaglutinação microscópica.

\section{INTRODUÇÃO}

A leptospirose é uma importante e complexa doença dos animais e do homem. sendo considerada uma das zoonoses mais difundida (Bolin, 1996).

Muitas espécies de animais silvestres podem atuar como reservatórios de Leptospira interrogans para outros animais silvestres ou domésticos e mesmo para o homem (Michna, 1970). Os roedores, principalmente o Mus musculus, Rattus rattus e particularmente o Rattus norvégicus são potenciais reservatórios dessa bactéria (Larigoni, 1999). O Rattus norvegicus é reconhecido mundialmente como reservatório do sorotipo icterohaemorrhagiaee, ocasionalmente, de outros sorotipos (Thiermann, 1981: Lindenbaum \& Eylan, 1982), enquanto o Mus musculus é reservatório para o sorotipo ballun (Hathaway et al., 1983; Alexander, 1984). Entretanto, o Rattus rattus é um reservatório menos freqüente de leptospira quando comparado com o Rattus norvegicus e o Mus muscuius (Hathaway \& Blackmore, 1981 ).
Em ratos, as leptospiras causam uma infecção sem sinais clínicos da doença, porém, os animais continuam a eliminar a bactéria portoda sua vida (Nicolescuet a/, 1973, Thiermann, 1981; Alexander, 1984).

Com relação ao rato de laboratório, Nicolescu et al. (1973), afirmaram que este animal pode se tomar reservatório do sorotipo icterohaemorrhagiae no mesmo grau que o rato silvestre. Caparão (1982) considerou a leptospirose como uma das infecçôes mais importante de animais de laboratório. Esta infecção foi descrita em biotérios de vários países (Nicolescu et al., 1973: Gefler, 1979; Fox \& Brayton, 1982; Pontes et al., 1990, Scanziani et al., 1995).

As fontes de infecção de leptospiras para colonias de ratos de laboratório podem ser reservatórios silvestres ou ratos e camundongos portadores deste microrganismo vindos de colônias não controladas (Nicolescu et al., 1973; Alexander, 1984). As principais formas de disseminação das leptospiras entre os animais da

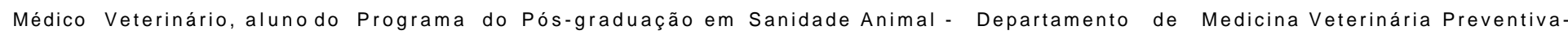
Centro de Ciências Agrárias-Universidade Estadual de Londrina.

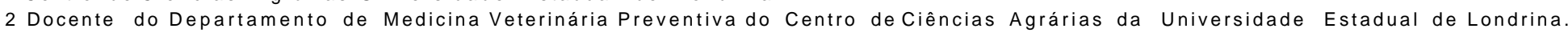


colônia são através do contato direto, durante o acasalamento, ou porlesões na pele (Loosli, 1967 apud Geller. 1979). Segundo Alexander (1984), a disseminação do microrganismo em biotério, entre animais de caixas diferentes, pode ocorrer através de frascos de água contaminados.

FOX \& Brayton (1982). Alexander (1984), Garcia et al. (1985) descreveram em biotérios os sorotipos australis, bataviae, grippotyphosa. hebdomadis, icterohacmonhagiae, pomona. pyrogenos, ballum.

Alexander (1984) considerou que a leptospirose em animais de biotério não é levada em consideração pela maioria dos fisiologistas. farmacologistas, psicólogos, bioquímicos, microbiologistas e outros cientistas que manuseiam estes animais.

O objetivo deste trabalho foi detectar a leptospirose através da prova de soroaglutinação microscópica, exame direto da urina e tentativas de isolamento em animais criados, mantidos e capturados nas proximidades do Biotério Central do Centro de Ciências Biológicas da Universidade Estadual de Londrina (BC-UEL).

\section{MATERIAL E MÉTODOS}

\subsection{Biotério}

O BC-UEL é composto pelo prédio principal construído em alvenaria, para cria e manutenção de ratos e camundongos que eram mantidos em salas específicas para cada espécie e ainda as salas de guarda de ração e da cama dos animais. Os ratos e camundongos eram mantidos em gaiolas especiais que abrigavam em média 4 a 5 e
10 a 15 animais respectivamente. Esta construção não permite a entrada de animais invasores.

$\mathrm{Na}$ área externa, em relação ao prédio principal, eram mantidos os cobaios, coelhos e cães. Os cobaios eram criados em baias teladas com o piso cimentado e os coelhos em gaiolas individuais suspensas, próprias para a espécie. Os cães eram mantidos em um canil composto de oito baias. As instalações onde eram mantidas as três espécies acima permitiam o acosso de pequenos roedores.

\subsection{Animais utilizados}

Dos animais criados e mantidos no biotério, foram utilizados neste experimento 325 ratos wistar adultos (Rattus norvegicus). 323 camundongos albinos adultos (Mus domesticus domesticus), $\quad 135$ coelhos adultos (Oryctotagus cunicuíus), 119 cobaios adultos (Cavia porcelius). Além destes animais, ainda foram utilizados 289 cães (Canis familiaris) de rua, capturados e enviados ao BC por prefeituras de oito municípios do Estado do Paraná e 57 ratos pretos (Rattus rattus) capturados na área externa próxima ao biotério (Tabela 1).

\subsection{Material examinado}

O soro utilizado para prova sorológica foi obtido de todos os 1248 animais deste experimento, enquanto que a urina para o exame direto foi obtida em uma única colheita de 282 camundongos albinos, 224 ratos wistar, 29 ratos pretos, 13 coelhos e de dois cobaios e de várias colheitas em 24 cães,

Tabela 1 - Animais utîlzados para o diagnástico de leptospirose entre maroorge a setembrorog.

\begin{tabular}{|c|c|c|c|c|c|c|}
\hline Espécies & Camundongo' & $\mathrm{C} \equiv 0^{2}$ & Soetho' & Cobaio' & Rato wislar & Rato preto \\
\hline Fophlaçào & 1.800 & 289 & 150 & 135 & 1.600 & \\
\hline Amostra & 317 & & 198 & 100 & 310 & \\
\hline Animais testados & 323 & 289 & 135 & 119 & 325 & 57 \\
\hline
\end{tabular}

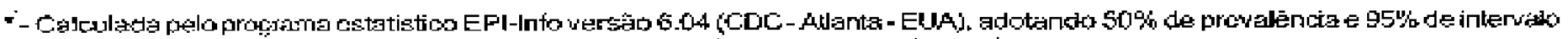
de contiança.

1 - Criadose mantidos, pelo BC-LJEL.

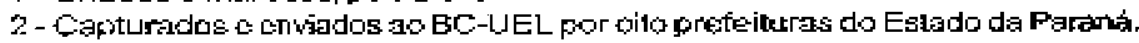

3- Capturadus nas poximidados do BC-LEL 
Para o isolamento de Leptospira spp. foram utilizados fragmentos dos rins e amostras de urina colhidas de três cães e de um cobaio positivos na soroaglutinação microscópica (SAM), e somente a urina de outros três cães também positivos na $S A M$.

Amostras de sangue foram colhidas corri seringa estéril segundo as recomendações para cada espécie. O sangue Foi mantido em frasco estéril até a retração do coágulo e então, somente o soro foi conservado a $-20^{\circ} \mathrm{O}$ até a realização do exame. A colheita da urina foi realizada por cistocentese com seringa estéril, sendo analisada imediatamente após a colheita.

\section{$2 A$ Exames realizados}

SAM: Foram utilizadas culturas vivas de 22 sorotipos de Leptospira interrogans (Tabela 2) cultivadas em meio EMJH modificado com albumina bovina, incubadas a $26{ }^{\circ} \mathrm{C}$ por 5 a 7 dias, contendo cerca de 100 bactérias por campo de $400 x$ de aumento. O soro foi diluído inicialmente a 1:50 em PBS $\mathrm{pH} \mathrm{7,2} \mathrm{e} \mathrm{distribuído} \mathrm{em} \mathrm{cubos} \mathrm{de} \mathrm{acordo} \mathrm{com}$ o número de sorotipos pesquisados. O sorotipo foi previamente diluído e adicionado no mesmo volume ao tubo contendo o soro. obtendo assim a diluição de $1: 100$. Os soros que apresentaram $2+$ ou mais de aglutinação nesta diluição foram considerados positivos e então diluídos seriadamente até a determinação da diluição maxima positiva. A leitura foi realizada em microscópio de campo escuro e interpretada de acordo com Myers (1985).

Exame direto da urina em microscópio de campo escuro (MCE): Uma gota da urina foi depositada em lâmina de vidro e examinada inicialmente em aumento de $200 x$ em microscópio de campo escuro (Santa Rosa, 1970). Foram consideradas positivas as amostras que apresentaram estruturas com morfologia e movimentação compatíveis á de espiroqueta.

Isolamento: Fragmentos dos rins e amostras de urina de três cães e um cobaio e somente urina de outros três cães foram semeados em meio de

Tabela 2 - Sorotipos de Leptospira interrogans utilizados para a realização do teste de soroaglutinaçao microscópica.

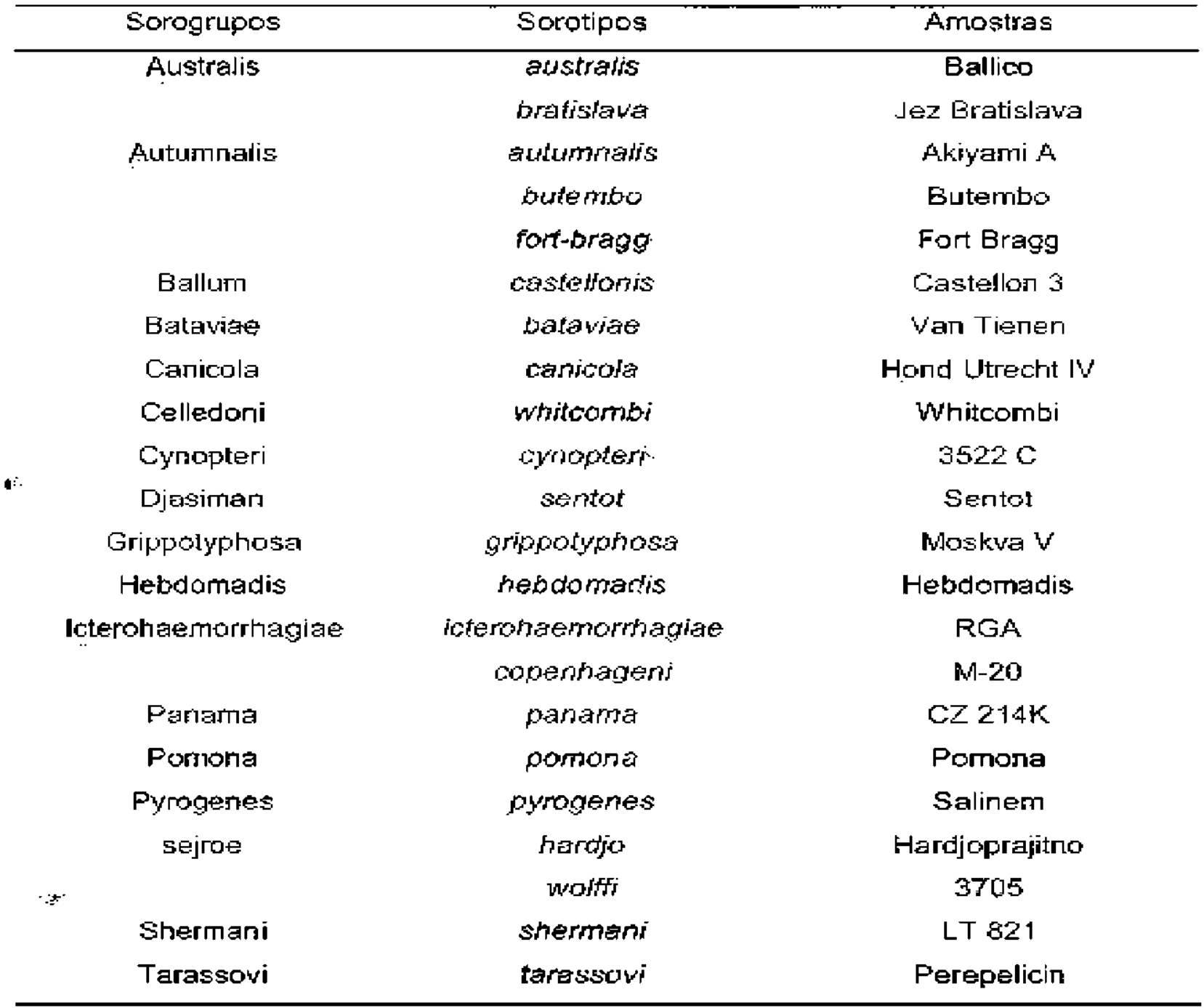


cultura EMJFI adicionado de 5-fluoro-uracil (Sigma) é então incubados a $28^{\circ} \mathrm{C}$ por até 60 dias. Semanalmente foram realizados controles em microscópio de campo escuro para verificar possível crescimento de leptospiras (Faine. 1982).

\section{RESULTADOS}

Dos 1248 animais de seis espécies do BC-UEL, testados pela prova de SAM. 110 cães e um cobaio apresentaram reação considerada positiva (Tabela 3). Títulos entre 100 e 400 foram detectados em 95 cães e entre 800 e 3200 em 15 cães, enquanto um cobaio apresentou titulo de 100 .

Em 49 cães $(44,54 \%)$ foram detectados anticorpos contra apenas um sorotipo de Leptospira interrogans e em 61 animais $(55,45 \%)$ contra dois ou mais sorotipos simultaneamente. Foram encontrados anticorpos contra o sorotipo canicola em 69 cães $(62,73 \%)$, contra o sorotipo pyrogenes em 57 cães $(51,81 \%)$. castellonis em $34(30,9 \%)$, icterobaemonhagiae em $26(23,63 \%)$, autumnaiis em $14 \quad(12,72 \%)$, grippotyphosa em $12(10.9 \%)$, copenhageni em 8 $(7,27 \%)$, butembo em seis $(5,45 \%)$, hebdomadis em cinco $(4,54 \%)$, fort bragg em quatro $(3.63 \%)$. cynopteriem quatro $(3,63 \%)$, sentot foi em três $(2,72 \%)$, bratislava em dois $(1,81 \%)$, bataviae em dois $(1,31 \%)$, pomona em dois $(1,81 \%)$, hardjo em um $(0,9 \%)$ e whiteombi em um $(0,9 \%)$.

O Único cobaio positivo na SAM apresentou anticorpos contra o sorotipo icterohaemorrbagiae.

O MCE de 574 animais mostrou a presença de estruturas com morfologia e movimento compatível com Leptospira spp em apenas seis cães (Tabela 3).

Foram negativas as sete tentativas de isolamento de Leptospira spp realizadas a partir de fragmentos de rim e urina do cobaio e dos cães positivo na SAM (Tabela 3 ).

Os oito municípios do Estado do Paraná que capturaram e enviaram cães de rua ao BC-UEL. tiveram entre 20,00 e $100 \%$ de animais considerados positivos na SAM (Tabela 4), devendo-se ressaltar o município de Nova Fátima com 10 (100\%) cães soropositivos.

\section{DISCUSSÃO}

Os resultados do presente estudo mostraram a presença de leptospirose no BC-UEL. Foi detectada evidência de infecção em 110 (38.06\%) dos 289 cães e em um (0.B4\%) dos 119 cobaios, enquanto que as demais espécies de animais estudadas apresentaram resultados negativos.

É bastante provável, que os $110(38,06 \%)$ cães mantidos no BC-UEL considerados positivos neste estudo, tenham se infectado nos locais de origem, pois todos eram animais de rua que foram capturados e enviados ao BC-UEL. Caldas et ai. (1977) consideraramquea forma de vida dos cães de rua torna-os mais expostos à infecção por leptospiras. Querino (1990) demonstrou que os cães que tinham acesso à rua tiveram 2,57 vezes mais chances de se infectarem do que os sem acesso a rua.

Tabela 3 - Resultados dos exames de soroaglutinação microscópica, exame direto da urina e tentativas de isolamento de Leptospira spp nas diferentes espécies de animais encontradas no BC-UEL no período de março/98 a seternbro/99.

\begin{tabular}{|c|c|c|c|c|c|c|c|c|c|}
\hline \multirow[t]{2}{*}{, Especies } & \multicolumn{3}{|c|}{ SAM } & \multicolumn{3}{|c|}{ MCE } & \multicolumn{3}{|c|}{ Isolamento } \\
\hline & $\pi$ & + & $\%$ & $\pi$ & 4. & $\%$ & $\bar{n}$ & t & $\%$ \\
\hline Camundongo & 323 & 0 & 0 & 282 & 0 & 9 & 0 & 0 & 0 \\
\hline Cobain & 119 & -1 & 0,84 & 2 & 0 & 0 & 1 & 9 & $\theta$ \\
\hline Coetho & 135 & 0 & 0 & 13 & 0 & 0 & 0 & 0 & 0 \\
\hline Câ & 289 & 110 & 38.06 & 24 & 6 & 25 & 6 & 0 & 0 \\
\hline Rato preto & 57 & 0 & 0 & 29 & 0 & 0 & 0 & 0 & 0 \\
\hline Rato wistar & 325 & 0 & D & 224 & $D$ & a & 0 & 0 & 0 \\
\hline TOTAL & 1.248 & 111 & 8,9 & 574 & 6 & 1,04 & 7 & 0 & 0 \\
\hline
\end{tabular}

n - Numero de snimgis examinados.

+ - Núrnero de anirinas positivos.

$\%$ - Foncentagem de arairnais posidivos.

GAM - Frova da sorogglutinacá microscopica.

|HCE - Examo direio da urina am microsoopio de campo escaro. 
Tabela 4 - Porcentagem dos caes de rua positivos na prova de soroaglutinacáo microscópica para L\&ptospira spp. capturados em oito municípios do Estado do Paraná.

\begin{tabular}{lccc}
\hline \multicolumn{1}{c}{ Municipios } & $\mathbf{n}$ & + & $\%$ \\
\hline Rio Branco do lvai & 44 & 12 & 27,27 \\
Rosário do lvai & 29 & 9 & 31,03 \\
Telemaco Borba & 88 & 40 & 45,45 \\
Leópolis & 29 & 9 & 31,03 \\
Nova Fátima & 10 & 10 & 100 \\
Congoinhas & 30 & 6 & 20 \\
Assai & 7 & 2 & 28,57 \\
Rolândia & 52 & 22 & 42,30 \\
Total & 289 & 110 & 38,06 \\
\hline
\end{tabular}

n-Nümero de cães.

+- Número de cầes positivas

$\%$ Porcentagem de cáes positivos.

Pontes et al, (1990) detectaram leptospiras em cães de rua mantidos no biotério da USP de Ribeirão Preto/SP e consideraram que a infecção nestes animais possa ter ocorrido tanto nos seus locais de origem (ruas da região de Ribeirão Preto) quanto no próprio biotério. pois o ambiente externo deste era propício á proliferação de roedores. Scanziani et al. (1995), na Itália e Grigoletto et al. (1999), no Rio Grande cio Sul demonstraram respectivamente a infecção por leptospiras em cães de laboratório e em cães do biotério do Hospital Veterinário da Universidade Federal de Santa Maria. Os primeiros autores consideraram o canil do origem destes animais como o local mais provável da infecção.

Os resultados negativos na SAM e MCE dos 57 ratos pretos capturados nos arredores do BCUEL estão de acordo com Hathaway \& Blackmore, (1981) que afirmaram que esta espécie de rato è um reservatório menos freqüente de leptospiras do que o rato marrom. Estes resultados ainda indicam que esta espécie animal não foi uma fonte de infeccão para os cobaios e coelhos criados e mantidos, respectivamente, em baias e gaiolas na área externa do BC-UEL, apesar do possível contato direto entre eles.

A fonte de infecção para o cobaio detectado com título considerado positivo não foi possível de ser determinada.

Resultados positivos para leptospiras têm sido registrados em camundongos albinos em biotérios de Cuba (Garcia et al. 1985). em macacos esquilo (Saimiri sciureus) no biotério do Instituto Pasteur da Guiana Francesa (Perolat ef al., 1992) e em ratos wistar, camundongos, cobaios e coelhos em biotério na índia (Natrajaseenivasan \& Ratnam, 1996). Nestes dois últimos biotérios, os ratos e outros roedores externos que tinham seu habitat próximo ao biotério e conseguiram penetrar nele, foram considerados como a fonte de infecção de leptospiras.

Os anticorpos detectados nos cães contra os sorotipos canicola $(62,7 \%)$ e icterohaemorrhagíae ( $23 \%$ ) são considerados quase que um padrão mundial. Estes resultados se justificam pelo modo de vida destes cães que favorece o contato entre eles que são os próprios reservatórios do sorotipocanicola, e também com roedores que são os reservatórios do sorotipo icterohaemorrhagiae. Foram detectados também anticorpos contra o sorotipo pyrogenes $(50,9 \%)$ nos animais estudados. Resultados semelhantes para este ultimo sorotipo $(45 \%)$ e $(52.55 \%)$, for am encontrados respectivamente por Querino (1999) trabalhando com cães do município de Londrina, Paraná e por Grigoíetto et a/. (1999) em cães de Santa Maria, Rio Grande do Sul. Além disso, este sorotipo foi isolado de cães na Argentina (Szyfres, 1976) e de rato d'água (Nectomys squamípes) no Brasil (Santa Rosa et ai-, 1980).

Dos vários municípios de origem dos cães de rua enviados ao BC-UEL, deve ser citado o município de Mova Fátima, que teve os 10 (100\%) cães soropositivos. Estes resultados indicam que esta bactéria pode estar amplamente distribuída entre os cães de rua daqueles municípios. 
Os resultados obtidos neste trabalho indicam que a leptospirose não está presente entre os animais criados e mantidos pelo BC-UEL mas os cães de rua capturados e apenas mantidos neste local, devem ser considerados como prováveis portadores de Leptospira sp p.

BELITARDO.D. R.; FREITAS. J. C. ; MÜLLER. E. E. Leptopirosis in animal of animal house of Biotogic Science Center of Londrina State University. Semina: Ci. Agrárias. Londrina, v. 21 .n. 1.p. 19-25, mar. 2000.

ABSTRACT: Leptospirosis has been described in laboratory animal house of several countries happening among mice. albino rats. guinea pigs, dogs, rabbits, monkeys and man. The laboratory animal house of Biologic Science Center of Londrina State University maintains and breeds several species of animals and stray dogs trapped in citíes of Paraná State. In this paper were utilized for leptospirosis research, 325 wistar rats. 323 albino mice. 289 dogs, 135 rabbits. 119 guinea pigs, and 57 black rats trapped around of animal house. The microscopic agglutination test with 22 cultures of Leptospira interrogans showed positive results in 110 dogs and one guinea pig, having been found antibodies against serovars canicola (62, 7\%), pyrogenes (51,8\%), castellonis (30.9\%) and icterobaemorrhagiae (23,6\%). The dark field microscopy examination of 574 urine samples (282 albino mice, 224 wistar rats, 29 black rats, 24 dogs, 13 rabbits and two guinea pigs) showed positive resuíts in six dogs. The seven attempts of urine and kidneys isolation were negatives.

KEY WORDS: Leptospirosis. animal house, microscopic agglutination test.

\section{REFERENCIAS BIBLIOGRÁFICAS}

ALEXANDER, A.D. Leptospirosis in Laboratory. Mice Science. v.224. n.465, p.1153, 1984.

BOLIN, C. A. Diagnosis of letospirosis: A reernerging disease of companion animals. Sem. Vet. Med. Surg. v.11, n.3, p. $166-171,1996$.

CALDAS. E. L. ; DORIA, J. D.; MARTINS. M. A. Imrnunological inquiry for the epidemiology of leptospirosis in Salvador, Bahia. Brazil. Int. J. Zoonoses. v.4. p. 103-110,1977.

C A PARÃO, A. C. Manual de patologia de animales de laboratório. Mexico: OPS, 1382. Cap. 1, Enfermidades infecciosas, p.12-13.

FAINE, S. Guidelines for the control of leptospirosis, Geneve: OPS, $1982,171 \mathrm{p}$. (WHO Offset Publication; n. 67)

FOX, J. G. ; BRAVTOIN, J. B. Zoonoses and other human heath hazards. In: FOSTER. HENRY.L.; SMALL. I. DAVID; FOX, JAMES. G. The mouse in bioquimicol research. New York: Academic Press. 1982. v 2, cap 22

GARCIA. M. J.; CORNIDE R.I.; GONZÁLEZ. A. Aislamento de Leptospira en animales convencionales. Mus musculus (variedad Albina) procedentes de un centro de cria tradicional. Rev. Cub. Med. Trop. v. 37, p. 341-347, Sep/ Dec. 1985

GELLER, E. H. In: The laboratory rat. New York: Academic Press, 1979. v. 1, cap. 15: Health hazards for man, p.402404 .

GRIGOLETTO, J.; GARGANO,R.; BADKE, M.R.T.etal. Pesquisa de aglutininas anti-leptospiricas nos cães do biotério do hospital veterinário. IN: CONGRESSO ESTADUAL DE MEDICINA VETERINÁRIA, 14., 1999 , Gramado. Anais..., Gramado, p. 131 .
HATHAWAY. S. C. ; BLACKMORE. D. K. Ecological aspects of the epidemiology of infection with leptospires of the Ballun seregrup in the black rat (Raffus rattus and brown rat (Rattus norvegicus\} in the $\mathrm{New}$ Zeland. J. Hyg. Camb, v. 87, p. $427-436,1981$.

HATHAWAY. S. C. ; BLACKMORE, D. K.; MARSHALL, R.B. Leptospirosis and the maintenance host: a laboratory house model. Res. Vet. Sc., n 34, p. 82-89, 1983.

LANGONI, H. Leptospirosis: animal and public health aspects. Continuous Education Journal. CRMV-SP., São Paulo. V. 2 , n. 1, p. $52-58,1999$.

LINDENBAUM, I. ; EYLAN, E. Leptospirosis in Raffus norvegicus and Rattos rattus in Israel. Israel. Med. Sci., v. 18, p 271-275. 1982 .

MICHNA, S. W. Leptospirosis. Vet. ReC, v.86. p.484-496,

MYERS. D. Leptospirosis: Manual de métodos para el diagnóstico de laboratório. Buenos Aires: Centro Panamericano de Zoonosese. 198. (Nota técnica 30).

NATRAJASEENtVASAN, K.: RATNAM. S. An invesfigation of leptospirosis in labojatony animal house. J. Gctmmun. Dls.. v 23 , n.S, p.ISS-157, 1i >9Lj.

NICOLESCU, M.; EORSAI, L.; ALAM1TA. I. Leptospirosis. in albino rals, Arss-i. \&v<im. P\&inos. Exp. Mierctbiot., $v 32$, n.2. p 171-177, 1373 ,

PEROLAT, P.P; POING, T. J.; VIE. J. et al. Occurrence of severe leptospirosis in a breeding colony of squirrel monkeys. Am. J. Trop. Mad. Hyg., v. 46, n. 5, p. 538-545, 1992.

PONTES, R. J. S. ; GIRIO.R. J. da S.; VENTURA. A. A. et al. Surto de leptospirose entre técnicos de laboratório do 
campus da Universidade de São Paulo do Ribeirão Preto.

1933. Medicina Ribeirão Preto, v. 23, n.3 p. 169-173, 1990.

QUERINO, A. M. V. Estado dos fatores de risco associados à

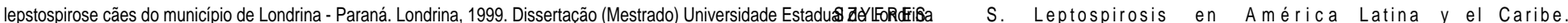
In.: REUNION INTERAMERICANA SOBRE ELCONTROLDE LA FIEBRE AFTOSA Y OTRAS ZOONOSIS. 8. 1976.

SANTA ROSA. C A. Diagnóstico labora;oriaí dos lepiospiroa-e-s. Rolt. klistQhia\}.. v.2, p. 97-1G9. 1070.

SANTA ROSA, C. A. ; SULZER.R. C. ; YAMAGUITA.R. M. et al. LTAROSA, C. A. ; SULZER. R. C. ; YAMAGUITA. R. M. et al. n. $7, p \cdot 1980$
SCAZIANI.

E.; CRIPPA, L.; GIUSTI. A. M. et al. Leptospira Interrogans serovar sejroc infection in a group of laboratory dogs. Lab. Animals, v. 29. p. 300-306, 1995. Washington.[Anales...]W ashington:OPS.1976.p.124-141.(Publica

THIERMANN, A. B. The norwav ra: as slective chronic carrier of Leptospira icterohaemorrhagiae, J. Wild. Dis. v.17,

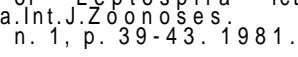

